\title{
Area-based Network of Health Workers to Mitigate the Shortage of Health Workforce: A Case Mix Index Approach for Thailand
}

Theepakorn Jithitikulchai ( $\nabla_{\text {jithitikulchai@hsph.harvard.edu ) }}$

Harvard T.H. Chan School of Public Health

Research

Keywords: health workforce, health resources, resource allocation, health catchment area, community health planning, community health network

Posted Date: March 15th, 2021

DOI: https://doi.org/10.21203/rs.3.rs-288165/v1

License: (c) (1) This work is licensed under a Creative Commons Attribution 4.0 International License.

Read Full License 


\section{Abstract}

\section{Background}

Public hospitals under the Office of Permanent Secretary, Ministry of Public Health have critical shortage in health workers. The area-based network consolidations of public hospitals should help to enhance capacity of the health system from allocation improvement in limited resources.

\section{Methods}

This study calculates the counterfactual simulations of area-based network allocations for health workforce in 10,500 public hospitals. The network consolidations at the sub-district, district, provincial, or health-region levels allow health workforce reallocation within local network areas. This study examines improvements in the allocative efficiency from the health workforce redistribution. The workload per worker is calculated from the output measured by numbers of outpatient and inpatient cases and the input measured by numbers of health workers. Both output and input are weighted with their economic values, controlled for heterogeneity by regression analysis. The weights assigned to each outpatient and inpatient case reflect the relative health system resources predicted for each discharge. Finally, this study compares the status quo and ex ante scenarios, as before and after network consolidations.

Results

Network consolidations of the primary-level hospitals within the same district could averagely reduce workload per worker by $14 \%$. Another practical policy option is that consolidating similar hospital levels such as primary, first-level secondary, and mid-level secondary hospitals altogether within the same district could reduce the workload per worker by $17 \%$.

\section{Conclusion}

This study illustrates improvement in allocative efficiency of health workforce in public hospitals from the area-based network consolidations. The results provide an insightful example of efficiency gains from reallocating medical workforce within the same local areas.

\section{Introduction}

Human resource planning of a health system has an important goal of having adequate health workforce with balanced allocation [1]. Major challenges of health resource allocation in Thailand are scarcity of health workforce and inequitable access to quality health care [2]. Thailand has faced the problem of demand for health services exceeding capacity of the public health system [3].

Thailand has inadequate health workforce less than the official requirements, even though the geographical allocations of health workers have been improved significantly over the last three decades with higher workforce availability. Nevertheless, public hospitals under the Office of Permanent Secretary 
in the Ministry of Public Health (MOPH) still have chronic shortages in health workforce. One of the reasons is insufficient budget [4]. Furthermore, there are geographical allocation issues such that the health workforce is more concentrated in Bangkok and big cities, and the inequity gap in proportions of targeted population to medical doctors could reach almost ten times among provinces [5].

The shortage of nurses has been a critical issue for Thai public health system, and the problem is expected to be more severe [6,7]. The nurse resignations are quite consecutively high because the health system cannot retain skilled and experienced nurses, unlike because of inadequate production of nurses in the previous three decades [8]. A study of 19,912 registered nurses revealed that 10 percent of the surveyed sample wanted to quit their career within the next two years [9]. Another study [10] found that young and less-skilled nurses have stronger intention to resign; while having less time off, less job satisfaction, or higher stress are significantly associated with probability of resignation. Other studies reported similar conclusions from community hospitals [11], a tertiary care hospital [12], and a university hospital [13].

Furthermore, Thailand will face higher demand for health workforce in different hospital levels such as primary [14] and tertiary [15]. The projections of demand and supply for medical specialists demonstrated severe shortages in almost all medical specialist professions as the consequences of aged society [16]. Therefore, here is the urgent issue for health workforce management to improve allocative efficiency, which is the government capacity to allocate limited resources to achieve desirable objectives.

Health resource planning requires not only to balance health workforce management for quantitative and qualitative goals, but also to adapt with varying health system needs. In particular, the effective reallocation for supply of medical workers in accordance with the demand of health care will lead to the more desirable clinical outcomes [17].

This study reports the area-based human resource allocation of hospitals under the Office of Permanent Secretary, the MOPH. The network consolidation should not only mitigate the health workforce shortage, but also to provide adequate quality services for people and enhance allocative efficiency of the health workers within their local areas.

The area-based network of health workforce is not a new concept for Thailand. But it has been developed and implemented by health system and medical staffs to collaborate in the district health administration systems [18-21].

Jithitiikulchai (2020) [22] studied the area-based network consolidations for health workforce in public hospitals to understand the shortage situation of each medical professions and estimate the shortage mitigation from network reallocations. However, Jithitiikulchai (2020) [22] considered each medical profession such as doctor, nurse, dentist, pharmacist, and others. Thus, this former research did not consider the aggregated output of health care service delivery units relative to the total health workforce, but only analyzed by medical profession based on number of health workforce relative to minimum manpower requirement. 
Therefore, this study endeavors to measure whether and how the area-based resource allocation at different levels of hospital services and administrative areas could mitigate the shortage in health workforce by considering the pooled health workforce. The research outcomes could provide an evidence to support the decisions on policy options to solve the health workforce shortage problems. This analytical application could be a useful example for other countries having shortage in health workforce for public hospitals.

\section{Methods}

The network consolidations are the area-based health system management that allows flexibility in health workforce reallocation to correspond the needs of population health within local administrativearea network areas at the district, provincial, or health-region levels.

This study considers network consolidations from different hospital classifications:

\section{All hospital levels}

2. Only the same hospital level

3. Similar hospital levels

3.1) Type A: \{Primary and First-level Secondary\} and \{Mid-level Secondary, High-level Secondary, and Tertiary\}

3.2) Type B: \{Primary, First-level Secondary, and Mid-level Secondary\} and \{High-level Secondary and Tertiary\}

The area-based network simulation is developed to quantify the hospital output and allocated to health workforce within the network. This approach is an application of gatekeeper concept to manage resources in according to the demand for health care service and the workforce supply capacity within each network.

The analysis compares workload per worker between (a) the hospital-level averages (status quo) and (b) the area-based network averages after consolidations at different administrative-area levels (ex-ante).

The key concept to measure output in this study is the weighted aggregation of medical treatment cases, where weights are the average medical costs incurred in the same hospital level. The hospital output is defined as the aggregation of the medical treatment cases weighted with the corresponding average costs.

This concept used to measure output is the case mix index (CMI) which provide reference for the standard inpatient costs for the diagnosis related group (DRG) as the adjusted relative weight (adjRW) [23]. However, this study directly calculated the average costs for outpatient and inpatient treatments with the regression analysis at different five hospital levels. But the same concept applies for both outpatient 
and inpatient cases to reflect the relative resource allocated for each discharge. Thus, the outpatient and inpatient cases can be weighted and aggregated as the hospital or network outputs.

The average costs of each treatment case are determined from the relevant attributes such as principal diagnosis (PDx), sex and age of patients, service time, service type, insurance type, total number of days admitted (only inpatient treatments), hospital, and health region. The cost regression functions which assign a relative value to each medical treatment case are calculated separately for outpatient and inpatient services at five different hospital levels. More details are available in Table S1 of Supplementary Material.

For the input factor, this study considers numbers of health workers by different professions, which are weighted by average hourly earnings and average work hours per week. Thus, the aggregation of the weighted numbers of health workers is the total workforce of hospitals or area-based networks.

The workload per worker is calculated from total output divided by total workforce. The workload per worker is then normalized by the average cost for outpatient treatments at the primary hospitals. Therefore, the results of average workload per worker are comparable using the same measurement unit as the numbers of outpatient cases from the primary-level health care service. Lastly, this study compares workload per worker for the hospital-level before network consolidations (status quo) and the network consolidations at different administrative-area levels (ex-ante).

\section{Data}

Numbers of each medical profession such as doctor, nurse, dentist, pharmacist, and other medical professions are the hospital-level data from the Human Resource Management Division of the Office of the Permanent Secretary, the MOPH.

The case-based data from the Information and Communication Technology Center of the MOPH covers principal diagnosis (PDx), sex, age, service time (office hours or after hours), service type (walk-in, referral, etc.), insurance type (Universal Coverage Scheme, Civil Servant Medical Benefit Scheme, Social Security Scheme, and others), total number of days admitted (inpatient treatments only), and costs of each treatment case.

The average hourly earnings and work hours per week of each medical profession are calculated from the Labor Force Survey (LFS) 2001Q1 to 2018 Q1 of the National Statistical Office. The regression functions of hourly earnings and work hours per week controlled for heterogeneity in age, gender, education, urban and rural areas, and province. The estimated hourly earnings and work hours per week are fixed at the year 2018. The hourly earnings were adjusted by temporal and spatial deflators. The health workers are selective by the ISCO-88 codes for the workers aged 15-64 employed in the public sector. The weights as adjustment factors are reported in Table $\mathrm{S} 2$ of Supplementary Material.

\section{Results}


The results are based on 10,500 public hospitals under the Office of the Permanent Secretary, MOPH across geographical units and health regions. The output in this study is based on $284,273,598$ outpatient discharges and 18,971,271 inpatient discharges in the budget year 2019. The outpatient and inpatient cases are weighted with their average costs. The average costs are controlled through linear regression estimations separately for different five hospitals levels. Tables S3-S4 in the Supplementary Material reports the regression results of cost of outpatient and inpatient cases.

The aggregations of weighted average costs of both outpatient and inpatient treatments in each hospital are normalized with the average cost of outpatient treatment in primary hospitals and resulted with $1,011,431,677$ normalized outpatient discharges in primary hospitals as the standardized output unit as outpatient cases. There are 157,508 health workforce which were calculated from numbers of workforce in different health professions weighted with their work hours per week and earnings per hour. Therefore, the output per worker has been normalized as the workloads of outpatient cases in primary hospitals for comparisons of the hospital-level averages (status quo) and the averages after consolidations (ex-ante).

The results of networking all public hospital levels combined altogether illustrates that the networking at the district levels can reduce the average workload per worker about $12 \%$ on average, as shown in Table 1 . The consolidations at the province and health region levels could reduce by $9 \%$ and $3 \%$. However, the network at the sub-district level has no impacts on average.

Table 1

Area-based network allocation of all service levels

\begin{tabular}{|llllll|}
\hline $\begin{array}{l}\text { All Hospital } \\
\text { Levels }\end{array}$ & Units & Workforce & $\begin{array}{l}\text { Normalized OP } \\
\text { cases }\end{array}$ & $\begin{array}{l}\text { OP cases per } \\
\text { worker }\end{array}$ & $\begin{array}{l}\text { Reduced OP cases per } \\
\text { worker }\end{array}$ \\
\hline Hospital & 10,500 & 250 & $2,553,796$ & 6,783 & \\
\hline Sub-district & 7,025 & 259 & $2,625,666$ & 6,763 & $0.3 \%$ \\
\hline District & 878 & 426 & $3,804,529$ & 5,998 & $11.6 \%$ \\
\hline Province & 76 & 2,786 & $19,080,767$ & 6,200 & $8.6 \%$ \\
\hline Health region & 12 & 13,448 & $84,338,899$ & 6,576 & $3.1 \%$ \\
\hline \begin{tabular}{l} 
Thailand \\
\hline
\end{tabular} & 1 & 157,508 & $1,011,431,677$ & 6,421 & $5.3 \%$ \\
\hline $\begin{array}{l}\text { Note: } \text { The reduced outpatient cases per worker in percentage is the fraction of the average cases per } \\
\text { worker after consolidation (ex-ante) compared to the average cases per worker of hospitals (status } \\
\text { quo). }\end{array}$
\end{tabular}

However, the networking within the same hospital level provides various results as shown in Table 2 . Consolidating at the primary level, networking at the district, province, and health region levels could reduce workload per worker by $14 \%, 20 \%$, and $26 \%$, respectively. For the first-level secondary hospitals, area-based networking cannot reduce the workload. For the mid-level secondary hospitals, networking at the province and health region levels could reduce workload per worker by $11 \%$. For the high-level 
secondary and the tertiary hospitals, the area-based network consolidations cannot improve the workload per worker. 
Table 2

Area-based network allocation by each service level

\begin{tabular}{|c|c|c|c|c|}
\hline vels & Units & Workforce & $\begin{array}{l}\text { Normalized OP } \\
\text { cases }\end{array}$ & $\begin{array}{l}\text { OP cases per } \\
\text { worker }\end{array}$ \\
\hline
\end{tabular}

\section{Primary}

\begin{tabular}{llllll} 
Hospital & 9,609 & 2 & 12,348 & 6,739 & \\
$\begin{array}{l}\text { Sub- } \\
\text { district }\end{array}$ & 6,548 & 4 & 20,870 & 6,730 & $0.1 \%$ \\
\hline District & 877 & 34 & 182,626 & 5,795 & $14.0 \%$ \\
\hline Province & 76 & 414 & $2,307,027$ & 5,389 & $20.0 \%$ \\
\hline $\begin{array}{l}\text { Health } \\
\text { region }\end{array}$ & 12 & 2,212 & $10,738,358$ & 4,986 & $26.0 \%$ \\
\hline Thailand & 1 & 26,750 & $123,386,219$ & 4,613 & $31.6 \%$
\end{tabular}

\subsection{First-level Secondary}

\begin{tabular}{llllll} 
Hospital & 508 & 75 & 371,240 & 4,741 & \\
$\begin{array}{l}\text { Sub- } \\
\text { district }\end{array}$ & 508 & 75 & 371,240 & 4,741 & $0.0 \%$ \\
\hline District & 502 & 76 & 377,815 & 4,738 & $0.0 \%$ \\
\hline Province & 66 & 776 & $4,567,067$ & 4,910 & $-3.6 \%$ \\
\hline $\begin{array}{l}\text { Health } \\
\text { region }\end{array}$ & 12 & 3,291 & $15,547,739$ & 4,812 & $-1.5 \%$ \\
\hline Thailand & 1 & 35,396 & $169,074,541$ & 4,777 & $-0.8 \%$
\end{tabular}

\subsection{Mid-level Secondary}

\begin{tabular}{lcclcc} 
Hospital & 264 & 105 & 404,464 & 4,306 & \\
$\begin{array}{l}\text { Sub- } \\
\text { district }\end{array}$ & 264 & 105 & 404,464 & 4,306 & $0.0 \%$ \\
\hline District & 260 & 108 & 411,322 & 4,307 & $0.0 \%$ \\
\hline Province & 65 & 605 & $2,228,892$ & 3,831 & $11.0 \%$ \\
\hline $\begin{array}{l}\text { Health } \\
\text { region }\end{array}$ & 12 & 2,445 & $8,802,865$ & 3,814 & $11.4 \%$ \\
\hline Thailand & 1 & 24,266 & $90,084,282$ & 3,712 & $13.8 \%$
\end{tabular}

Note: The reduced outpatient cases per worker in percentage is the fraction of the average cases per worker after consolidation (ex-ante) compared to the average cases per worker of hospitals (status quo). 


\begin{tabular}{|c|c|c|c|c|c|}
\hline Levels & Units & Workforce & $\begin{array}{l}\text { Normalized OP } \\
\text { cases }\end{array}$ & $\begin{array}{l}\text { OP cases per } \\
\text { worker }\end{array}$ & $\begin{array}{l}\text { Reduced OP cases per } \\
\text { worker }\end{array}$ \\
\hline \multicolumn{6}{|c|}{ 2.3 High-level Secondary } \\
\hline Hospital & 84 & 510 & $4,338,017$ & 6,405 & \\
\hline $\begin{array}{l}\text { Sub- } \\
\text { district }\end{array}$ & 84 & 510 & $4,338,017$ & 6,405 & $0.0 \%$ \\
\hline District & 84 & 510 & $4,338,017$ & 6,405 & $0.0 \%$ \\
\hline Province & 61 & 756 & $6,118,850$ & 6,266 & $2.2 \%$ \\
\hline $\begin{array}{l}\text { Health } \\
\text { region }\end{array}$ & 12 & 2,950 & $20,184,971$ & 6,638 & $-3.7 \%$ \\
\hline Thailand & 1 & 35,280 & $199,036,643$ & 5,642 & $11.9 \%$ \\
\hline \multicolumn{6}{|l|}{ 3. Tertiary } \\
\hline Hospital & 35 & 1,158 & $13,086,724$ & 10,359 & \\
\hline $\begin{array}{l}\text { Sub- } \\
\text { district }\end{array}$ & 35 & 1,158 & $13,086,724$ & 10,359 & $0.0 \%$ \\
\hline District & 35 & 1,158 & $13,086,724$ & 10,359 & $0.0 \%$ \\
\hline Province & 34 & 1,166 & $13,126,641$ & 10,360 & $0.0 \%$ \\
\hline $\begin{array}{l}\text { Health } \\
\text { region }\end{array}$ & 12 & 3,567 & $33,872,948$ & 11,851 & $-14.4 \%$ \\
\hline Thailand & 1 & 35,816 & $429,849,992$ & 12,002 & $-15.9 \%$ \\
\hline \multicolumn{6}{|c|}{$\begin{array}{l}\text { Note: The reduced outpatient cases per worker in percentage is the fraction of the average cases per } \\
\text { worker after consolidation (ex-ante) compared to the average cases per worker of hospitals (status } \\
\text { quo). }\end{array}$} \\
\hline
\end{tabular}

For the networking of similar hospital levels, there are two options as illustrated in Table 3a-3b. The results show that both options of network consolidations for the similar hospital levels could reduce the average workload per worker for the lower hospital levels which are \{Primary and First-level Secondary\} of Option A and \{Primary, First-level Secondary, and Mid-level Secondary\} of Option B. When combined at the district level, Option A could reduce the workload by $13 \%$, while Option B could reduce the workload by $17 \%$, on average.

However, both options for the upper hospital levels, such as \{Mid-level Secondary, High-level Secondary, and Tertiary\} of Option A and \{High-level Secondary and Tertiary\} of Option B could not reduce the average cases per worker. 
Table 3

a: Area-based network allocation by clustered service level (Option A)

\begin{tabular}{|llllll|}
\hline Levels & Units & Workforce & $\begin{array}{l}\text { Normalized OP } \\
\text { cases }\end{array}$ & $\begin{array}{l}\text { OP cases per } \\
\text { worker }\end{array}$ & $\begin{array}{l}\text { Reduced OP cases per } \\
\text { worker }\end{array}$ \\
\hline Primary and First-level Secondary & & & \\
\hline Hospital & 10,117 & 17 & 85,747 & 6,306 & $0.4 \%$ \\
\hline $\begin{array}{l}\text { Sub- } \\
\text { district }\end{array}$ & 6,803 & 20 & 100,532 & 6,283 & $12.6 \%$ \\
\hline District & 878 & 76 & 403,343 & 5,512 & $19.5 \%$ \\
\hline Province & 76 & 1,085 & $6,111,913$ & 5,076 & $20.1 \%$ \\
\hline $\begin{array}{l}\text { Health } \\
\text { region }\end{array}$ & 12 & 5,249 & $26,157,213$ & 5,038 & $25.4 \%$ \\
\hline $\begin{array}{l}\text { Thailand } \\
\text { Mid-level Secondary, High-level Secondary, and Tertiary }\end{array}$ & 1 & 62,146 & $292,460,760$ & 4,706 & \\
\hline Hospital & 383 & 697 & $7,273,117$ & 7,644 & $0.0 \%$ \\
\hline $\begin{array}{l}\text { Sub- } \\
\text { district }\end{array}$ & 383 & 697 & $7,273,117$ & 7,644 & $-0.4 \%$ \\
\hline District & 376 & 708 & $7,327,152$ & 7,674 & $2.9 \%$ \\
\hline Province & 76 & 1,814 & $13,319,879$ & 7,423 & $-3.3 \%$ \\
\hline $\begin{array}{l}\text { Health } \\
\text { region }\end{array}$ & 12 & 8,683 & $61,598,598$ & 7,900 & $1.4 \%$ \\
\hline \begin{tabular}{l} 
Thailand \\
\hline
\end{tabular} & 1 & 95,362 & $718,970,917$ & 7,539 & \\
\hline
\end{tabular}


Table 3

b: Area-based network allocation by clustered service level (Option B)

\begin{tabular}{|c|c|c|c|c|c|}
\hline Levels & Units & Workforce & $\begin{array}{l}\text { Normalized OP } \\
\text { cases }\end{array}$ & $\begin{array}{l}\text { OP cases per } \\
\text { worker }\end{array}$ & $\begin{array}{l}\text { Reduced OP cases per } \\
\text { worker }\end{array}$ \\
\hline \multicolumn{6}{|c|}{ Primary, First-level Secondary, and Mid-level Secondary } \\
\hline Hospital & 10,381 & 28 & 125,298 & 6,046 & \\
\hline $\begin{array}{l}\text { Sub- } \\
\text { district }\end{array}$ & 6,940 & 32 & 142,042 & 6,022 & $0.4 \%$ \\
\hline District & 878 & 104 & 510,207 & 4,999 & $17.3 \%$ \\
\hline Province & 76 & 1,522 & $7,812,893$ & 4,792 & $20.7 \%$ \\
\hline $\begin{array}{l}\text { Health } \\
\text { region }\end{array}$ & 12 & 7,388 & $34,320,695$ & 4,748 & $21.5 \%$ \\
\hline Thailand & 1 & 86,412 & $382,545,042$ & 4,427 & $26.8 \%$ \\
\hline \multicolumn{6}{|c|}{ High-level Secondary and Tertiary } \\
\hline Hospital & 119 & 916 & $9,825,265$ & 8,885 & \\
\hline $\begin{array}{l}\text { Sub- } \\
\text { district }\end{array}$ & 119 & 916 & $9,825,265$ & 8,885 & $0.0 \%$ \\
\hline District & 116 & 940 & $10,003,507$ & 8,977 & $-1.0 \%$ \\
\hline Province & 76 & 1,306 & $13,061,744$ & 8,989 & $-1.2 \%$ \\
\hline $\begin{array}{l}\text { Health } \\
\text { region }\end{array}$ & 12 & 6,388 & $55,692,574$ & 9,367 & $-5.4 \%$ \\
\hline Thailand & 1 & 71,096 & $628,886,635$ & 8,846 & $0.4 \%$ \\
\hline
\end{tabular}

\section{Discussion}

The area-based networks can redistribute the health workforce to provide health care services with better flexibility in resource management. From a practical perspective, networking the primary-level hospitals within the same district could reduce workload per worker by $14 \%$ on the national average. Another feasible policy option is consolidating the similar hospital levels such as primary, first-level secondary, and mid-level secondary hospitals which could reduce the workload per worker by $17 \%$.

The network consolidations are based on some assumptions that health workers could simply move within the network. However, the health service units are practically independent to each other on 
planning, budgeting, and performance assessment. Furthermore, current health system does not allow such flexibility to reflect in promotion and career path for public health workers in Thailand.

Therefore, this requires what Leerapan et al. (2018) [24] proposed as "major reforms of MOPH care delivery models" such that the health care delivery units can adjust and adapt their resources and services in corresponding to the population health needs. This includes the capacity reallocation of health care delivery teams to enlarge in the areas with excess demand and to reduce in the areas with excess supply. This proposal of "major reforms of MOPH care delivery models" is consistent with the allocative efficiency, such that the health system has management capacity to establish and prioritize objectives to shift health system resources in corresponding to numerous impediments and targeted result accomplishments.

Noree et al. (2017) [25] defined distinguished properties of the desirable health care delivery system as a seamless health service network of an integrated system of primary, secondary, and tertiary hospitals. Pooling resources and planning through the management information system within local network are important for a strong referral healthcare management system with gatekeeper. Both Leerapan et al. (2018) and Noree et al. (2017) [24-25] are aligned with the goal of the "value-based health care" concept [26-27], which is a health care delivery model to maximize the value of care for patients and minimizing the cost of health care.

As the quantitative evaluations in this study are based on the results at average, this study provides value to some extent for the policy options for allocation of public health workers to mitigate workforce shortage. However, a good policy is not one-size-fits-all. It requires decentralization for the provincial and district health systems to have their own autonomy over decision-making and equipped with accountability to monitor and evaluate their performance through the health resource information system.

The area-based heath care delivery management such as the district or provincial level could add commuting burden to the health workers. Therefore, we should have financial incentives, career advancement mechanism, and team development programs, among others to facilitate the local health care system development.

Furthermore, the political economy analysis of area-based network development could be useful to define political strategies to reduce the opponent force and enhance the supports among stakeholders within the health system.

Finally, any countries with the community health network policies should have a national strategic plan for area-based health care delivery system development that is aligned with the national human resource plan of their health system.

\section{Limitation}


First, this study has some limitations on total output calculations. Health workforce positions have responsibility not only on treatment service delivery used in this study. They also have some other tasks such as health promotion and disease prevention services, and administrative works, among others. Due to data limitations, this study cannot consider other tasks beyond the outpatient and inpatient discharges.

Second, the area-based network consolidations at the district, provincial, and health-region levels in this study implicitly assumed that the health workforce can move freely withing the network to serve the local health care needs. However, the calculations are only for technical results for the policy makers to consider policy and program options on human resource management. It requires considerate evaluations of positive and negative externalities potentially occurred to the health workers within each hospital and local area. The practical possibilities in author's opinion are to consolidate primary hospitals within each district (which has already been practiced), similar hospital levels within each province, or mixed of both. The final decisions should be considered together by health provincial office, health district offices, and hospitals.

Lastly, the value in health care this study used the value of each treatment service deliverable case as the unit cost in general economic sense. However, Porter $(2006,2010)$ [26-27] suggested that achieving goal of health care delivery requires that the value should be defined as the health outcomes achieved per every monetary unit spent. Therefore, relevant research in the future can measure the value of each discharge with the framework for performance improvement in health care that create value for patients, measured by the outcomes achieved, not inputs nor volume of services delivered.

\section{Conclusion}

This study evaluates the shortage mitigation and efficiency gain from the area-based network of health workers for the hospitals. The analytical results confirm improvement in allocative efficiency of health workforce in public hospitals from network consolidations.

\section{Abbreviations}

CSMBS: Civil Servant Medical Benefit Scheme; MOPH: Thai Ministry of Public Health; PDx: principal diagnosis; SSS: Social Security Scheme; UCS: Universal Coverage Scheme

\section{Declarations}

\section{Acknowledgements}

The author acknowledges the financial support received from the Health Systems Research Institute of Thailand. 


\section{Funding}

The research received funding from the Health Systems Research Institute of Thailand.

\section{Availability of data and materials}

The datasets used for this study are available from the corresponding author upon reasonable request and with the authorized approvals from the government offices which own the original raw data.

\section{Author's contributions}

TJ solely worked on the study.

\section{Ethics approval and consent to participate}

Not applicable as secondary and anonymous data was used in the study.

\section{Consent for publication}

Not applicable.

\section{Competing interests}

The author declares to have no competing interests.

\section{References}

1. Pagaiya N. Human resources for health requirements projection: Crucial baseline to support human resources for health planning. Journal of Health Systems Research 2018;12(2):342-55.

2. Noree T, Thanomwat $Y$, Phanthunane P, and Gongkulawat K. Research for synthesize options and policy recommendations for planning the human resources for health needs in the future decade. Final Report. The Human Resources for Health Research and Development Office (HRDO). International Health Policy Program (IHPP); 2017.

3. Leerapan B, Teekasap P, Jaichuen W, Chiangchaisakulthai K, Cooper Meeyai A, Urwannachotima N, et al. Report of data collection and synthesis of Thailand's demands for health workforce in the next 20 years. Final Report; 2018. 
4. Working Group on Efficiency Development of System Resources Allocation. Public Health Steering and Reform Sub-committee for Health Finance and Universal Health Coverage. A study project for proposal on UHC financing for efficiency development of system resources allocation: Human resources for health. Final Report; 2016.

5. Strategy and Planning Division PSO, Ministry of Public Health. Report on public health resources in 2016. Nonthaburi: Ministry of Public Health; 2018.

6. Srisuphan W and Sawangdee K. Policy recommendation for nurse shortage in Thailand. Thai Journal of Nursing Council 2012;27(5)5-12.

7. Pagaiya N, Phanthunane P, Bamrung A, Noree T, and Kongweerakul K. Forecasting imbalances of human resources for health in the Thailand health service system: application of a health demand method. Human Resources for Health 2019;17(4)1-12.

8. Sawaengdee K. Crisis of nursing shortage in health service facilities under the Office of Permanent Secretary, Ministry of Public Health: Policy recommendations. Journal of Health Science 2017;26(2):457-68.

9. Sawaengdee $K$, Tangcharoensathien $V$, Theerawit $T$, Thungjaroenkul P, Thinkhamrop W, Prathumkam P, Chaichaya N, Thinkhamrop K, Tawarungruang C, and Thinkhamrop B. Thai nurse cohort study: cohort profiles and key findings. BMC Nursing 2016;5(10)1-12.

10. Seema K, Intaraprasong B, Pattara-achachai J. Registered nurse's intention to leave the profession in Bangkok Metropolitan Administration hospitals. Journal of Nursing Division 2015;42(3):142-58.

11. Thongniran N, Intaraprasong B, and Pattara-Archachai J. Intention to stay in occupation of registered nurses at a community hospital region 1: Central, Thailand. Journal of Nursing Division 2015;42(3): 69-83.

12. Muneerat S, Suwannapong N, Tipayamongkholgul M, Manmee C. Job characteristics, job-related stress and intention to stay in professional nursing in a tertiary care hospital, Ministry of Public Health. Journal of Health Science 2019;28(1)133-41.

13. Jeawkok J, Dhammasaccakarn W, Keawpimon P. Retention and intention of resignation to the job of registered nurses in the university hospital, Songkhla Province. NIDA Development Journal 2015;55(3):109-44.

14. Pagaiya N, Khaonuan B, Phanthunane P, Bamrung A, and Jirawattanapisal T. Human resources for health projections for primary health care services in Thailand 2026. Journal of Health Systems Research 2018;12(2):189-204.

15. Phanthunane P, Bamrung A, Jirawattanapisal T, Pagaiya N, Khaonuan B, and Noree T. A utilizationbased model to predict human resources for health $(\mathrm{HRH})$ in secondary care services of Thailand 2026. Journal of Health Systems Research 2018;12(2):205-20.

16. Phanthunane P, Pannarunothai $P$, and Pagaiya N. Requirement and supply projection of selected medical specialists in Thailand in 2021. Malaysian Journal of Public Health Medicine 2017;17(2):709. 
17. Leelarasamee A, Intragumtornchai T, Pannarunothai S, Laohavinij S, Patjanasoontorn B, Suntorntham S, et al. Need for internal medicine subspecialists in Thailand. J Med Assoc Thai 2017;100(2):239-253.

18. Hasuwannakit S. Network management for contracted unit for primary care (CUP). Nonthaburi: Office of Community Based Health Care Research and Development; 2007.

19. Bookboon P. Population-centered district health system development. Nonthaburi: Office of Community Based Health Care Research and Development; 2016.

20. Office of Community Based Health Care Research and Development. Family physicians: Driving force for NCDs. Synthesis from NCD 2015 Forum; Nonthaburi; 2018 a.

21. Office of Community Based Health Care Research and Development. Lessons from district health system administration: Participatory primary health worker and network management; Nonthaburi; 2018b.

22. Jithitikulchai T. Area-based network allocations: a solution to mitigate the shortage of health workforce. Journal of Health Systems Research 2020;14(3):243-73.

23. Suphanchaimat R. "Health Insurance Card Scheme" for cross-border migrants in Thailand: Responses in policy implementation \& outcome evaluation. Doctoral dissertation. London School of Hygiene \& Tropical Medicine; 2017.

24. Noree T, Thanormwat Y, Phanthunane P, and Gongkulawat K. 2017. Research Project on Synthesis of Alternatives and Policy Recommendation for Planning Health Workforce in the Next Decade (20172026). International Health Policy Program. Ministry of Public Health.

25. Leerapan B, Teekasap P, Jaichuen W, Chiangchaisakulthai K, Meeyai AC, Urwannachotima N, and Udomaksorn K. 2018. Strategic planning of human resources for health to address the challenges of Thailand's Universal Health Coverage: A system dynamics approach. Final Report to the Office of Permanent Secretary, Ministry of Public Health.

26. Porter ME, Teisberg EO. Redefining health care: creating value-based competition on results. Boston: Harvard Business School Press; 2006.

27. Porter ME, Teisberg EO. What Is Value in Health Care? New England Journal of Medicine 2010;363(26): 2477-81.

\section{Supplementary Files}

This is a list of supplementary files associated with this preprint. Click to download.

- SupplementaryMaterial.docx 